\title{
Oral bisphosphonate compliance and persistence: a matter of choice?
}

\author{
S. L. Silverman • J. T. Schousboe • D. T. Gold
}

Received: 10 December 2009/Accepted: 29 March 2010/Published online: 11 May 2010

(C) The Author(s) 2010. This article is published with open access at Springerlink.com

\begin{abstract}
Compliance to oral bisphosphonates is suboptimal, with negative consequences of increased healthcare utilization and less effective fracture risk reduction. Extending dose interval increased adherence only moderately. We used literature derived from multiple chronic conditions to examine the problem of noncompliance with osteoporosis medication. We reviewed the literature on adherence to osteoporosis medication as well as that across multiple chronic conditions to understand what is known about the cause of the poor adherence. Poor compliance to oral medications is due mostly, not to forgetfulness, but to deliberate choice. Gender differences and style of healthcare management also play a role. Preliminary data suggest psychobehavioral interventions may help to improve motivation. We need to understand better reasons for poor compliance before effective interventions can be developed. Forgetfulness is only a small part of poor compliance. Patient preferences must be considered in medication decision making.
\end{abstract}

Keywords Osteoporosis · Medication adherence . Fractures $\cdot$ Bones

S. L. Silverman $(\bowtie)$

Cedars-Sinai/UCLA/OMC,

8641 Wilshire Blvd., Suite 301,

Beverly Hills, CA 90211, USA

e-mail: stuarts@omcresearch.org

J. T. Schousboe

Department of Rheumatology, Park Nicollet Medical Center,

St. Louis Park, MN, USA

D. T. Gold

Psychiatry and Behavioral Sciences, Sociology, and Psychology

and Neuroscience, Duke University Medical School,

Durham, NC, USA

\section{Introduction}

The primary challenge in treating chronic illness today is that many chronically ill patients do not take their prescription medications correctly. As the US Surgeon General C. Everett Koop has said, "Drugs don't work in patients who don't take them...." There has been much concern about the negative consequences of poor compliance and persistence with oral osteoporosis medications. This article will briefly review these issues and, more specifically, will address possible reasons why patients may not take their oral osteoporosis therapies as directed, and suggest some potential solutions and future research. We will focus on oral bisphosphonates since the majority of the prescriptions for a medication for fracture prevention are for an oral bisphosphonate.

\section{Compliance and persistence with therapy}

What has become apparent in research done during the last few years is that many patients discontinue oral medications for osteoporosis soon after treatment initiation, with a rapid drop in persistence in the first 3 months, followed by a slower decline over ensuing months. For example, persistence on daily bisphosphonate therapy has varied between $25 \%$ and $35 \%$ persistence at 1 year [1]. Persistence with weekly bisphosphonate therapy at 1 year is between $35 \%$ and $45 \%$, a rate not substantially better [1]. Some improvement in persistence was seen in one study with monthly bisphosphonate therapy using administrative claims data, but this improvement has not been confirmed in other studies [2-4]. Adherence to estrogen agonists/antagonists such as raloxifene may be somewhat higher [5], as well as anabolic agents such as teriparitide which require daily subcutane- 
ous injections [6]. The adherence reported to bisphosphonate medications depends on the methodology used, whether medication possession ratio or persistence over a specific time period is used as well as the definition of the refill gap. This poor persistence seen with oral bisphosphonates does not differ substantially from the persistence to oral medications prescribed for other largely asymptomatic chronic conditions such as hypertension [7] and hypercholesterolemia [8]. Osteoporosis itself is asymptomatic until a fracture occurs, and some patients can have multiple vertebral fractures before symptoms appear.

Evidence suggests across multiple therapeutic areas that many patients take drugs incorrectly, infrequently, or not at all. A 2002 Harris Interactive Study [9] showed that approximately $18 \%$ of patients taking medications for one or more chronic illnesses had not filled their prescriptions at all, $26 \%$ had delayed filling their prescriptions, $14 \%$ took a prescription medication in a smaller dose than prescribed, approximately $30 \%$ had taken a prescription medication less often than prescribed, and approximately $21 \%$ had stopped taking medication sooner than prescribed. While such a study has not yet been done in patients with osteoporosis, we anticipate that the results of one would be similar to those reported here.

Noncompliance and nonpersistence can occur at three discrete points. Patients can be noncompliant by not filling their prescription; they can be noncompliant by not initially taking their medicine as directed by their physician (correct dosing and time and manner of administration), or they can be noncompliant by missing doses. They can also stop their medication without telling their healthcare providers (nonpersistence).

\section{Consequences of poor compliance and persistence}

Poor compliance and persistence with osteoporosis medications lead to diminished medication efficacy and, therefore, to less suppression of bone turnover [10] and lower gains in bone mineral density [11]. These in turn lead to higher fracture rates, [12-15], medical costs, and greater healthcare utilization including higher hospitalization rates [16].

Some refill compliance studies in patients with osteoporosis have examined the relationship between such compliance and fracture. Siris et al. [17] found that minimal and/or no effect on fracture risk is with refill compliance below $50 \%$, and a curvilinear decrease in probability of fracture is with refill compliance over $50 \%$. In contrast, Curtis et al. did not find a threshold level of compliance below which there was no fracture reduction benefit, but rather a curvilinear effect throughout all ranges of refill compliance [18]. Similarly, among patients with osteopo- rosis by bone mineral density criteria, Rabenda et al. [14] found a linear relationship between hip fracture reduction benefit and medication possession ratio throughout the entire range of refill compliance.

Perhaps the most striking point was made by Feldstein [19] who found similar time to first fracture over an 8-year period of patients with osteoporosis as defined by bone density or fracture in patients who were treated with oral bisphosphonates versus those who were not treated with an osteoporosis medication. Her study suggests that although oral bisphosphonates are efficacious in randomized clinical trials (within which persistence and compliance are typically high), their efficacy does not translate to the community setting when patients do not fill their prescriptions, do not take their medications as prescribed, and are not persistent.

\section{Reasons for noncompliance}

Direct experience of adverse effects (such as stomach upset from an oral bisphosphonate) accounts for a significant proportion of nonpersistence and noncompliance. Even without directly experienced side effects, however, patients may stop their medication for a number of reasons [20]. They may not believe that they have osteoporosis or that they are not at much risk of fracture (e.g., they do not have a problem that requires a solution). For some individuals, future potential health issues are not a salient issue for them in their lives, such that even if they acknowledge a high risk of future fractures, they place a lower value on interventions to reduce that risk [21, 22]. Patients may be skeptical of the effectiveness of the medication or worried about longterm harm from or feeling dependent upon medication. Even if they do acknowledge that the medication does effectively reduce fractures, they may believe they can address the problem adequately through non-medicinal interventions (e.g., nutritional interventions such as calcium and vitamin D and exercise). The cost of the medication may be a barrier for them [23]. Any combination of these reasons may lead a person to choose nonpersistence with fracture prevention medication. Discrete choice experiments suggest that patients weigh perceived risks and benefits when they form their intention as to whether they take a medication or not. They consider the perceived benefit of the medication, its cost (i.e., cost and time), and perceived risks of side effects $[24,25]$. As many as one fifth or more of patients do not fill their prescriptions [26].

Even if patients form an intention to take medication for osteoporosis, they may have difficulty executing medication use behavior in the context of their daily 
lives. Lack of perceived ability to take the medication as prescribed (poor self-efficacy) [27], complex dosing schedules that interfere with daily activities, lack of social support to aid their medication use activities, and simply forgetting to take the medication may result in nonpersistence or noncompliance [20] In these instances, poor compliance may be unintentional.

As noted previously, in the 2002 Harris Interactive Study of Persistence and Compliance [9], patients were asked why they did not fill prescriptions or comply with drug regimens. Twenty-four percent of the patients suggested that they occasionally forget to refill a prescription, while another $20 \%$ did not want to experience real or perceived side effects. Cost was a barrier for $17 \%$ of these patients, and another $14 \%$ felt they did not really need the drug. Interestingly, this study revealed that another important factor in compliance and persistence may be the patient's own management style. The researchers found that, in chronic diseases, patients for whom maintaining a sense of control is important are most likely not to fill a prescription, fill a prescription on time, continue taking a prescription, and take it as frequently as prescribed or in sufficient doses than patients who are less concerned about maintaining a sense of control. Future research is needed to ascertain whether or not these individuals are more likely to feel dependent on medication when using it, and if that is the source of their sense of lack of control associated with its use. The Harris study also found that there were gender differences in medication behaviors, with women less likely than men to report compliance with prescribed drug regimens; however, other studies have reported lower compliance among men [28].

The perspectives of physician and patient often differ substantially [20,29]. Although both physicians and patients consider efficacy, safety, and cost, they are likely to differ in their estimates or beliefs about these in part because they have different belief systems and use different sources of information. Patients increasingly gather information from the Internet, while also depending on peers, friends, and family. Physicians, on the other hand, rely on published data from randomized clinical trials, professional guidelines, and opinions of key thought leaders. Patients often base their safety concerns on both real and perceived side effects. Physicians think about costs to the healthcare system as well as to the patient while patients focus on their own out of pocket costs. Physicians may concentrate on negative messaging (e.g., if you do not take your medication you will fracture and you will be in a wheelchair) while patients respond to positive messaging (if you take your medicine you will have a better quality of life and be able to play with your grandchildren) [30].

\section{Generalizability}

In this review, we have focused on oral bisphosphonates since the majority of scripts are for oral bisphosphonates. Most studies have focused on oral bisphosphonates. There is some modest data on raloxifene (ref) which shows similarly poor compliance on therapy and data on $\operatorname{rhPTH}(1-34)$ which also shows poor compliance to this daily injectable therapy. We do not know compliance on parenteral bisphosphonates but if we are correct that a substantial proportion of poor persistence is intentional, then the use of IV drugs is not likely to fully address the problem of poor persistence. An individual needs to go to a healthcare provider to get the IV therapy. There has been no extensive study of compliance to vitamin $\mathrm{D}$, but studies of compliance to vitamin $\mathrm{D}$ would be worthwhile.

\section{How we can improve compliance and persistence}

The research literature suggests that the most effective compliance and persistence intervention may simply be to increase interaction with healthcare providers. Clowes et al. [31] did a randomized clinical trial to study compliance and persistence in osteoporosis with patients randomized to one of three groups: no monitoring, nurse monitoring, and nurse plus bone marker monitoring. Both of the monitored groups showed better persistence than did the no-monitoring group, but there was no significant difference between nurses monitoring alone compared to nurse plus marker monitoring. In the Delmas [32] IMPACT trial, patients who had a positive response to therapy as judged by urine biomarkers and were given positive feedback had better adherence (i.e., compliance) than patients who received negative feedback from biomarkers.

Therapeutic interventions to improve medication-related behaviors across multiple chronic conditions have often failed. In a review by Haynes [33], only 36 out of 81 adherence interventions led to improved outcomes with modest improvements in persistence and clinical outcomes. Most of the interventions have emphasized use of pill reminders, pill organizers, increasing convenience which do not address intentional poor compliance. The majority of the successful interventions involved more than one type of intervention (e.g., education combined with selfmanagement) $[33,34]$ and involved some level of engaging the patient to influences, health beliefs, and attitudes they have regarding their underlying disease and the recommended medication.

Compliance and persistence are extremely important for a variety of people with interest and investment in osteoporosis. Stakeholders for compliance and persistence 
include healthcare providers, pharmaceutical companies, family, friends, and pharmacists; however, the major stakeholder - the one in the middle of this circle - is the patient. All of these stakeholders could play a potential role in improving compliance and persistence.

Opportunities to improve compliance and persistence occur at several points after a patient receives the diagnosis of osteoporosis. While writing the prescription, healthcare providers could attempt to identify high-risk patients who initially may not even fill the prescription. High-risk patients could be identified [35] by using a questionnaire or by review of compliance with other medications [36]. After a patient fills a prescription, more traditional patientand physician-centered strategies might enhance patient behaviors. Patient-centered solutions include use of alternative packaging [37], loyalty incentive programs, letter, texting or e-mail reminder programs $[38,39]$, and patient educational tools including use of call centers [40]. Lowering cost may have a significant positive effect, but other factors are even more important [23]. Strategies for physicians have included electronic reminders, education of the importance of compliance and persistence, and pay for performance.

However, both traditional patient- and physiciancentered strategies have not been successful in improving compliance and persistence [41] in part due to participant bias in these interventions. Patients who participate in these programs are often the patients most interested and invested in their care (e.g., for whom the health value of the medication is high and understand the connection between their health behaviors and health outcomes). Patients for whom the health value of the medication is lower are more likely to be noncompliant and are unlikely to participate in these programs. These individuals may tend to be more passive in managing their health and may not see the connection between their own health behaviors and the resulting health outcomes.

Recently, commercial programs have attempted to improve compliance and persistence [42] by adding patient support through motivational interviewing techniques [43, 44], which attempt to modify patient behaviors and "activate" patients to improve their health behaviors. These behavioral techniques help patients by identifying personal goals, by helping them understand how fractures would impede their ability to realize those goals, and by using interviewing techniques done by behavioral coaches to help motivate patients to be able to make a more realistic appraisal of the risks and benefits of medication use. These techniques may help improve patients' self-efficacy [27] or confidence that they can take their medication in the context of their daily lives and become better selfmanagers. Unfortunately, such behavioral interventions are time intensive and costly. However, such interven- tions could be cost-effective if they result in significant healthcare savings from preventing fractures. What we need is to be able to deliver a behavioral intervention with cost-effective technology. One such possibility is to use the Internet or DVDs to disseminate educational material to activate patients based on elicited patient preferences and health beliefs.

Poor persistence and compliance is a significant problem in the management of osteoporosis. The primary reason patients with osteoporosis do not take their medicines is most likely not simply forgetting to do so. The majority of patients are actively choosing not to take their medications. Why they make these choices varies. The effect of improving patients taking their medications by $20 \%$ is equivalent to a roughly $20 \%$ improvement in efficacy [45]. We need to be thinking about interventions which not only extend dosing intervals but also utilize multifaceted strategies to improve compliance and persistence. These must start when the prescription is written and continue throughout the entire medication-taking interval.

\section{Further research}

Future research on compliance and persistence should be concentrated in three main areas. First, we need to better understand the process by which patients form intentions to take or not take recommended medication. Secondly, we need to understand the roles of patient time preference in patient decision-making, which refers to the degree that patients are willing to expend resources such as time, money, or bother now to prevent adverse events such as fracture which may or may not happen in the future. We also need to understand patient risk preferences in terms of fracture risk and side effects. What level of fracture risk motivates a patient to take a medication and, similarly, what level of perceived side effects will motivate a patient to discontinue a medication or not fill the prescription? Finally, using this information, we need to develop means to help healthcare providers identify patients who are at high risk of poor compliance and/or persistence. This may include questionnaires [35] or by reviewing persistence to other chronic medications [36]. We then need to develop interventions solidly based on educational theory which will activate those patients at high risk of osteoporosis to be more involved in their care and become more compliant and persistent with medication regimens. These interventions may require the services of allied health professionals skilled in behavioral coaching and motivational interviewing techniques. Such programs will of course carry a direct 
medical cost. Research in the future will be required to estimate how effective such programs are in improving compliance with osteoporosis medications, and how cost-effective are these interventions.

\section{Conclusions}

Compliance and persistence with osteoporosis therapy is less than optimal. However, compliance and persistence in osteoporosis is not significantly different from other asymptomatic chronic conditions. Most of the poor medication behavior with osteoporosis medication is probably intentional rather than unintentional. There is a need to develop multifaceted interventions to improve compliance and persistence with osteoporosis medications.

\section{Conflicts of interest None.}

Open Access This article is distributed under the terms of the Creative Commons Attribution Noncommercial License which permits any noncommercial use, distribution, and reproduction in any medium, provided the original author(s) and source are credited.

\section{References}

1. Cramer JA, Gold DT, Silverman SL, Lewiecki EM (2007) A systematic review of persistence and compliance with bisphosphonates for osteoporosis. Osteoporos Int 18:1023-1031

2. Silverman SL, Cramer JA, Sunyecz JA, et al (2007) Women are more persistent with monthly bisphosphonate therapy compared to weekly bisphosphonates: 12 month results from two retrospective databases. Presented at ASBMR Montreal, 19 Sept 2007. Abstract W366

3. Cotte FE, Fardelione P, Mercier F, Gaudin AF, Roux C (2009) Adherence to monthly and weekly oral bisphosphonates in women with osteoporosis. Osteoporos Int 29(1):125-139

4. Gold DT, Safi W, Trinh H (2006) Patient preference and adherence: comparative US studies between two bisphosphonates, weekly risedronate and monthly ibandronate. Curr Med Res Opin 22(12):2383-2391

5. Gorai I, Tanaka Y, Hattori S, Iwaoki Y (2010) Assessment of adherence to treatment of postmenopausal osteoporosis with raloxifene or alfacalcidol in postmenopausal Japanese women. J Bone Miner Metab 28:176-184

6. Arden NK, Earl S, Fisher DJ et al (2006) Persistence with teriparitide in patients with osteoporosis: the UK experience. Osteoporos Int 17:1626-1629

7. Vrijens B, Vincze G, Kristanto P, Urquhart J, Burnier M (2008) Adherence to prescribed antihypertensive drug treatments: longitudinal study of electronically compiled dosing histories. BMJ 336(7653):1114-1117

8. Jackevicius CA, Mamdani M, Tu JV (2002) Adherence with statin therapy in elderly patients with and without acute coronary syndromes. JAMA 288:462-467

9. Boston Consulting Group (BCG) (2002) Analysis: Harris interactive 10,000 patient survey 2002. Available at: http://www.bcg.com/ documents/file14265.pdf. Accessed: 21 Oct 2009
10. Reginster JY (2006) Adherence and persistence: impact and outcomes and health care resources. Bone 38(2 Suppl 2):S18S21

11. Yood RA, Emani S, Reed JI, Lewis BE, Charpentier M, Lydick E (2003) Compliance with pharmacologic therapy for osteoporosis. Osteoporos Int 14:965-968

12. Weycker D, Macarios D, Edelsberg J, Oster G (2007) Compliance with osteoporosis drug therapy and risk of fracture. Osteoporos Int $18: 271-277$

13. Huybrechts KF, Ishak KJ, Caro JJ (2006) Assessment of compliance with osteoporosis treatment and its consequences in a managed care population. Bone 38:922-928

14. Rabenda V, Mertens R, Fabri V, Vanoverloop J, Sumkay F, Vannecke C, Deswaef A, Verpooten GA, Reginster JY (2008) Adherence to bisphosphonates therapy and hip fracture risk in osteoporotic women. Osteoporos Int 19:811-818

15. Caro JJ, Ishak KJ, Kf H, Raggio G, Naujoks C (2004) The impact of compliance with osteoporosis therapies on fracture rates in actual practice. Osteoporos Int 15:1003-1008

16. McCombs JS, Thiebaud P, McLaughlin-Miley C, Shi J (2004) Compliance with drug therapies for the prevention and treatment of osteoporosis. Maturitas 48:271-287

17. Siris ES, Harris ST, Cj R, Barr CE, Arvesen JN, Abbott TA, Silverman S (2006) Adherence to bisphosphonate therapy and fracture rates in osteoporotic women: relationship to vertebral and nonvertebral fractures from 2 US claims databases. Mayo Clin Proc 81:1013-1022

18. Curtis JR, Westfall AO, Cheng H, Lyles k, Saag K, Delzell E (2008) Benefit of adherence with bisphosphonates depends on the age and fracture type: results from an analysis of 101,038 new bisphosphonate users. J Bone Miner Res 23:1435-1441

19. Feldstein A (2009) Effectiveness of bisphosphonate therapy in a community setting. Bone 44:153-159

20. Silverman SL, Gold DT (2008) Compliance and persistence with osteoporosis therapies. Curr Rheumatol Rep 10(2):118-122

21. Cline RR, Farley JF, Hansen RA, Schommer JC (2005) Osteoporosis beliefs and antiresorptive medication use. Maturitas 50:196-208

22. McHorney CA, Schousboe JT, Cline RR, Weiss TW (2007) The impact of osteoporosis medication beliefs and side effect experiences on non-adherence to oral bisphosphonates. Curr Med Res Opin 23:3137-3152

23. Liel Y, Castel H, Bonneh DY (2003) Impact of subsidizing effective anti-osteoporosis drugs on compliance with management guidelines in patients following low impact fractures. Osteoporos Int 14:490-495

24. de Bekker-Grob EW, Essink-Bot ML, Meerding WJ, Pols HAP, Koes BW, Steyerberg EW (2008) Patients' preferences for osteoporosis drug treatment: a discrete choice experiment. Osteoporos Int 19:1029-1037

25. Fraenkel L, Constantinescu F, Oberto Medina M, Wittink DR (2006) Womens preferences for prevention of bone loss. J Rheumatol 32:1086-1092

26. Karter AJ, Parker MM, Moffet HH, Ahmed AT, Ja S, Selby JV (2009) New prescription medication gaps: a comprehensive measure of adherence to new prescriptions. Health Serv Res 44:1445-1448

27. Schwarzer R, Fuchs R (1995) Self-efficacy and health behaviors. In: Connor M, Norman P (eds) Predicting health behavior. Open University Press, Philadelphia, pp 163-196

28. Carnevale V, Nieddu L, Romagnoli E, Bona E, Piemonte S, Scillitani A, Minisola S (2006) Osteoporosis intervention in ambulatory patients with previous hip fracture: a multicentric, nationwide Italian study. Osteoporos Int 17:478-483

29. Donovan JL (1995) Patient decision making. The missing ingredient in compliance research. Int $\mathrm{J}$ Technol Assess Health Care 11(3):443-455 
30. International Osteoporosis Foundation (2005) The adherence gap: why osteoporosis patients don't continue with treatment. Nyon, Switzerland

31. Clowes JA, Peel NF, Eastell R (2004) The impact of monitoring on adherence and persistence with antiresorptive treatment for postmenopausal osteoporosis: a randomized controlled trial. J Clin Endocrinol Metab 89:1117-1123

32. Delmas PD, Vrijens B, Eastell R, Roux C, Pois HA, Ringe JD, Grauer A, Cahall D, Watts NB, Improving Measurements of Persistence on Actonel Treatment (IMPACT) Investigators (2007) Effect of monitoring bone turnover markers on persistence with risedronate treatment of postmenopausal osteoporosis. J Clin Endocrinol Metab 92:1296-1304

33. Haynes RB, Ackloo E, Sahota N, McDonald HP, Yao X (2008) Interventions for enhancing medication adherence. Cochrane Database Syst Rev 16(2):CD000011

34. Gleeson T, Iversen MD, Avorn J, Brookhart AM, Katz JN, Losina E, May F, Patrick AR, Shrank WH, Solomon DH (2009) Interventions to improve adherence and persistence with osteoporosis medications: a systematic literature review. Osteoporos Int. doi:10.1007/s00198-009-0976-0

35. Morisky DE, Ang A, Krousel-Wood M, Ward HJ (2008) Predictive validity of a medication adherence measure in an outpatient setting. J Clin Hypertens (Greenwich) 10:348-354

36. Curtis JR, Xi J, Westfall AO, Cheng H, Lyles K, Saag KG, Delzell E (2009) Improving the prediction of medication compliance: the example of bisphosphonates for osteoporosis. Med Care 47:334341
37. Schneider PJ, Murphy JE, Pedersen CA (2003) Impact of medication packaging on adherence and treatment outcomes in older ambulatory patients. J Am Pharm Assoc 48:58-63

38. Cocosila M, Archer N, Haynes RB, Yuan Y (2009) Can wireless text messaging improve adherence to preventive activities? Results of a randomized controlled trial. Int J Med Inform 78:230-238

39. Hayes TL, Cobbinah K, Dishongh T, Kaye JA, Kimel J, Labhard M, Leen T, Lundell J, Ozertem U, Pvael M, Phillipose M, Rhodes K, Vurgun S (2009) A study of medication taking and unobtrusive, intelligent reminding. Telemed J E Health 15:770-776

40. Young RJ, Taylor J, Friede T, Hollis S, Mason JM, Lee P, Burns E, Long AF, Gambling T, New JP, Gibson JM (2005) Pro-active call center treatment support (PACCTS) to improve glucose control in type 2 diabetes: a randomized controlled trial. Diabetes Care 28:278-282

41. Warriner AH, Curtis JR (2009) Adherence to osteoporosis treatments: room for improvement. Curr Opin Rheumatol 21:356-362

42. Cooper A, Drake J, Brankin E, PERSIST Investigators (2006) Treatment persistence withonce-monthly ibandronate and patient support vs once weekly alendronate: results from the PERSIST trial. Int J Clin Pract 60:896-905

43. Miller WR, Rollnick S (2002) Motivational interviewing: preparing people for change. Guilford Press, New York

44. Swanson AJ, Pantalon MV, Cohen KR (1999) Motivational interviewing and treatment adherence among psychiatric and dually diagnosed patients. J Nerv Ment Disease 187:630-635

45. Cotte FE, Fautrel B, Pouvourville G De (2009) A Markov model simulation of the effect of treatment persistence in postmenopausal osteoporosis. Med Decis Making 29:125-139 